\title{
O programa de Matemática dos cursos industriais básicos da Escola Técnica Nacional
}

(1942-1965)

Paulo Roberto Castor Maciel ${ }^{1}$

Universidade do Estado do Rio de Janeiro (UERJ), Faculdade de Educação da Baixada Fluminense, Departamento de Educação Matemática, Duque de Caxias, RJ, Brasil

\section{Resumo}

Este trabalho tem por objetivo analisar o programa de Matemática dos cursos industriais básicos de 1946 da Escola Técnica Nacional (ETN). Utilizou-se a pesquisa histórica, fundamentado nas ideias da história das disciplinas escolares. Inicialmente apresentou-se como surgiu a disciplina atemática do ginásio, identificou-se os conteúdos ao longo das reformas que aconteceram durante o período das décadas de 1930 a 1950. Posteriormente identificou-se os conteúdos do programa da ETN durante o mesmo período. Confrontou-se tal programa com os do ginásio e constatou-se que havia semelhanças entre eles. Sob a perspectiva dos conteúdos fixados no programa e do ensino praticado na escola, também se observou que havia uma harmonia entre esses itens. Dessa forma, conclui-se que tal programa era parecido com o programa do ginásio e que as disciplinas das distintas modalidades eram similares.

Palavras-chave: História da Educação Matemática; Ensino Industrial; Programa de Matemática.

\section{The Mathematics program of the basic industrial courses of the National Technical School}

(1942-1965)

\begin{abstract}
This paper aims to analyze the mathematics program of the basic industrial courses of 1946 of the National Technical School (ETN). Historical research was used, based on the ideas of the history of school subjects. Initially, it was presented how the Mathematics discipline at the Gymnasium appeared, the contents were identified during the reforms that took place during the period from the 1930 s to the 1950s. Subsequently, the contents of the ETN program during the same period were identified. This program was compared with those in the gym and it was found that there were similarities between them. From the perspective of the contents fixed in the program and the teaching practiced at school, it was also observed that there was a harmony between these items. Thus, it is concluded that such a program was similar to the gym program and that the disciplines of the different modalities were similar.
\end{abstract}

Keywords: History of Mathematics Education; Industrial Education; Mathematics Program.

Submetido em: 06/04/2020

Aceito em: 13/05/2020

Publicado em: 20/06/2020

${ }^{1}$ Doutor em Ciência, Tecnologia e Educação pelo Centro Federal de Educação Tecnológica Celso Suckow da Fonseca (CEFET/RJ). Professor do Departamento de Educação Matemática da Faculdade de Educação da Baixada Fluminense da Universidade do Estado do Rio de Janeiro (UERJ). Endereço para correspondência: Rua General Manoel Rabelo, s/nVila São Luis - Duque de Caxias-RJ - CEP: 25065-050. E-mail: prcastor@hotmail.com 


\section{El programa de Matemáticas de los cursos industriales básicos de la Escuela Técnica Nacional}

(1942-1965)

\section{Resumen}

Este trabajo tiene como objetivo analizar el programa de matemáticas de los cursos industriales básicos de 1946 de la Escuela Técnica Nacional (ETN). Se utilizó la investigación histórica, basada en las ideas de la historia de las asignaturas escolares. Inicialmente, se presentó cómo apareció la disciplina de Matemáticas en el Gymnasium, se identificaron los contenidos durante las reformas que tuvieron lugar durante el período de 1930 a 1950. Posteriormente, se identificaron los contenidos del programa ETN durante el mismo período. Este programa se comparó con los del gimnasio y se descubrió que había similitudes entre ellos. Desde la perspectiva de los contenidos fijados en el programa y la enseñanza practicada en la escuela, también se observó que había una armonía entre estos elementos. Por lo tanto, se concluye que dicho programa era similar al programa de gimnasio y que las disciplinas de las diferentes modalidades eran similares.

Palabras clave: Historia de la Educación Matemática; Educacion Industrial; programa de matemáticas.

\section{Introdução}

A Escola Técnica Nacional (ETN) foi criada pelo decreto $n^{\circ} 4127$, de 25 de fevereiro de 1942, durante o Governo de Getúlio Vargas, e integrava a rede federal de escolas técnicas industriais. A trajetória da ETN se inicia por meio de um cenário de conjunturas sociopolíticas e econômicas na década de 1940. Nesse período, o ensino profissional esteve ligado a propostas desenvolvimentistas da indústria e por isso a necessidade de formação de mão de obra especializada. A instituição passou por diversas mudanças até consolidar-se e atualmente é conhecida como Centro Federal de Educação Tecnológica Celso Suckow da Fonseca (CEFET/RJ).

Durante o governo Vargas, foram adotadas medidas que impactavam o campo da educação, como a criação do Ministério da Educação e Saúde Pública (MESP); a Reforma Francisco Campos; a Constituição Federal de 1934; e a Reforma Capanema. A criação do MESP marcou a importância das áreas de educação e saúde, que foram temáticas debatidas durante toda a década de 1920. Em 1931, assumiu o ministério Francisco Campos, que, em 1934, foi substituído por Gustavo Capanema.

Francisco Campos foi o primeiro titular a assumir o Ministério da Educação e Saúde Pública, criado durante o governo provisório de Vargas. A reforma educacional que ele realizou sistematizou em nível nacional a educação nos ensinos: secundário, superior e comercial. Segundo Romanelli (2013, p. 133), era o “[...] início de uma ação mais objetiva do Estado em relação à educação”. Dentre os itens da reforma, citamos a instituição da universidade como modelo para o ensino superior e a criação do Conselho Nacional de Educação. Houve também a organização do ensino secundário e do ensino comercial. Essa reforma foi influenciada por muitas discussões que aconteceram na década de 1920 e que envolveram dois grupos: os católicos e os renovadores. Assim, com a Reforma houve um 
atendimento das demandas dos grupos ligados à Igreja e institui-se a disciplina de ensino religioso de forma facultativa, ao mesmo tempo que foram também aceitas ideias da Escola Nova.

O Decreto $n^{\circ} 19.890$ de 1931 foi responsável pelo processo de sistematização do ensino secundário. Segundo Dallabrida (2009), a reforma proporcionou uma modernização do ensino secundário no País, pois conferiu organicidade a esse nível de ensino por meio de uma série de medidas, dentre elas o aumento do número de anos desse segmento de ensino, a divisão em dois ciclos e a seriação do currículo, além de exigência de frequência nas aulas. Com a Reforma Francisco Campos, o ensino secundário ficou dividido em dois ciclos. O primeiro foi chamado de curso fundamental e ficou estruturado em cinco séries. O segundo ciclo foi chamado de curso complementar tinha duração de dois anos. Neste artigo, daremos ênfase ao curso fundamental. A disciplina de Matemática aparecia em todas as séries do curso fundamental.

Depois da Reforma de 1931, unificaram-se em uma única disciplina as áreas de Aritmética, de Álgebra e de Geometria, que antes eram ensinadas de forma separada.

Em 1934, Gustavo Capanema assumiu o Ministério da Educação e Saúde Pública e realizou uma nova reforma educacional a partir de Leis Orgânicas do Ensino, que regulamentaram o ensino primário, secundário, normal, comercial e industrial. O Decreto-lei no 4244, de 9 de abril de 1942, ficou conhecido como Lei Orgânica do Ensino Secundário. Capanema promoveu mudanças nessa modalidade, mas preservou a divisão do secundário, realizada pela Reforma Francisco Campos, em dois ciclos. Durante esse período, Capanema também institui a Lei Orgânica do Ensino Industrial pelo Decreto-lei n ${ }^{\circ} 4073$, de 30 de janeiro de 1942, e se propunha a formar profissionais para atuar na indústria, promover qualificação profissional aos jovens e adultos não diplomados ou habilitados, aperfeiçoar ou especializar os trabalhadores diplomados e divulgar conhecimentos de atualidades técnicas (BRASIL, 1942). Foi por meio da Lei Orgânica do Ensino Industrial que se agruparam as duas estratégias para a formação de profissionais para a indústria (CUNHA, 1980). É dentro desse contexto que a ETN surgiu como uma das escolas voltadas para a indústria, integrando uma rede federal de escolas técnicas e industriais.

O ensino industrial seguia também o padrão adotado para o ensino secundário sendo dividido em dois ciclos. $\mathrm{O} 1^{\mathrm{o}}$ ciclo contava com cursos industriais, cuja duração era de quatro anos e se articulavam com o ginásio do ensino secundário; o $2^{\circ}$ ciclo contava com o curso técnico, cuja duração era de três anos, sendo equivalente a colégio (cursos científico e clássico).

No presente trabalho, optou-se por delimitar a análise ao programa dos cursos industriais básicos, que eram compostos por disciplinas de cultura geral, comuns a todos os cursos e disciplinas de cultura específica que estavam relacionadas com a profissão escolhida. 
O foco deste artigo é a disciplina de Matemática, ministrada nos quatro anos dos cursos industriais básicos e que tinham carga horária de três horas semanais. Com isso, temos como questão principal para nosso trabalho: qual o programa da ETN de matemática e os conteúdos propostos para tal nível de ensino? Outra questão a ser identificada a partir do confronto do programa da ETN com o do ginásio é se havia similaridade ou não com a modalidade de ensino secundário. A partir do currículo escrito da referida instituição será possível concluir se ele estava em harmonia com a prática escolar na sala de aula. Nosso trabalho se justifica pela lacuna de estudos sobre a disciplina de Matemática em modalidades diferentes do ensino secundário (MACIEL, 2018), tendo em vista que o foco das pesquisas históricas existentes tem se voltado para o ensino regular em detrimento do ensino profissional. O trabalho pretende contribuir para a discussão sobre a disciplina em diferentes modalidades de ensino a partir da identificação dos conteúdos fixados na ETN. No caso específico dessa investigação será possível constatar como se comporta a matemática num ambiente escolar que tinha como objetivo a formação de mão de obra qualificada para a indústria.

\section{Fundamentação Teórica}

Nesta investigação utilizou-se a pesquisa histórica. De acordo com Bloch (2001), a história “é a ciência dos homens no tempo" e por isso é considerado que a questão da caracterização e da identificação curricular se dá primeiramente pela construção de um homem específico, em uma dada sociedade e pelas demandas nas quais estava inserido.

Nessa perspectiva, Certeau (2011, p. 47) considera que “[...] toda pesquisa historiográfica se articula com um lugar de produção socioeconômico, político e cultural”. No caso da ETN, foi criada durante o Estado Novo, alinhada com uma postura de desenvolvimentismo industrial, o qual demandava um quantitativo de mão de obra especializada para as novas fábricas.

A partir da identificação das questões político-econômicas, sociais e culturais às quais a ETN estava submetida, é possível entender as interferências ocorridas no processo de formação, uma vez que, por meio dos instrumentos oferecidos pela história cultural, consegue-se identificar o modo como em diferentes locais e momentos uma realidade social foi construída, pensada e dada a ler (CHARTIER, 2002). Tal proposta deve ser realizada a partir dos vestígios do passado que, neste trabalho, são os documentos escolares que serviram de fontes para a investigação.

Utilizamos como aporte teórico metodológico as ideias da história das disciplinas escolares de três autores: Chervel (1990), Viñao (2008) e Goodson (1997).

A partir da análise dos documentos pertencentes à ETN, é importante definir as finalidades do ensino, que, segundo Chervel (1990), é um problema complexo e sutil e que se confronta com a história do ensino. Ensino esse que está relacionado à história das disciplinas escolares, que deve 
identificar, classificar e organizar os objetivos ou finalidades. Assim, busca-se, a partir do estudo da disciplina Matemática, construir um panorama sobre as finalidades do ensino empreendido, a partir dos conteúdos matemáticos que eram ensinados.

Segundo Chervel (1990), a documentação a ser analisada inicialmente deve ser: textos oficiais programáticos, discursos ministeriais, leis, decretos, programas etc. Na etapa seguinte, devem ser analisados objetivos fixados e a realidade pedagógica, que permite inferir se houve a execução ou não do que foi planejado pelos documentos como programas. O referido autor afirma que, para descrever uma disciplina, é preciso apresentar os conteúdos e descriminar detalhadamente suas etapas, o que pode contribuir para constatar as ligações entre ensino dispensado e as finalidades dele.

Viñao (2008, p. 206) afirma que "[...] o elemento-chave, que configura, organiza e ordena uma disciplina é o código disciplinar”. E os seguintes componentes o constituem: corpo de conteúdos (que podem conter em programas, cadernos, livros e exames); discurso sobre o valor formativo e utilidade (tais discursos podem ser constituídos para apresentar a importância da disciplina, determinar adequação dos conteúdos a demandas do setor produtivo e ser proferidos em eventos, comunicações, nos livros textos e nas conversas); e as práticas profissionais (que estão relacionadas à prática docente em sala). Dessa forma, identificar os conteúdos é uma parte importante do código, e, por isso, devemos investigá-los nos programas e nos livros textos. Assim, pretendemos realizar tal estudo com relação a disciplina da ETN.

Goodson (1997, p. 26) afirma que é importante examinar “[...] a relação entre o conteúdo e a forma da disciplina escolar, e de analisar as questões da prática e dos processos escolares". Tal ideia nos remete a identificar a disciplina e sua caracterização a partir dos conteúdos listados.

De acordo com o referido autor, o currículo é um artefato social que foi concebido para a realização de objetivos específicos da sociedade. Afirma também que, quando se utiliza o currículo como fonte histórica, surgem alguns problemas pelo fato do conceito ser ilusório e multifacetado. Além disso, considera o programa e as orientações como currículo escrito que possui um significado simbólico e prático. O fato de ser simbólico está relacionado às intenções educativas que são comunicadas e legitimas. Já o fato de ser prático está de acordo com as convenções feitas a partir da sua escrita e acabam tornando recursos e benefícios.

O currículo escrito de uma disciplina é um processo complexo na visão de Goodson (1997) e merece destaque até mesmo para que possam ser analisadas as práticas docentes.

A fonte principal para este trabalho foi o programa destinado para os cursos industriais básicos de matemática encontrado no Relatório do ano de 1946. Tal documento foi encontrado no Setor de Arquivos do CEFET/RJ (SEARQ). No entanto, utilizamos outras fontes como legislação, manuais didáticos para auxiliar no processo de comparação e análise do referido programa da disciplina. 
Assim, deve-se interrogar as fontes de maneira que se possa obter respostas para as perguntas formuladas e, com isso, perceber que tais vestígios do passado são produto de um processo de seleção que pode ter ocorrido de forma consciente ou não (LE GOFF, 1990).

Para verificar se os conteúdos fixados pelo programa foram inseridos efetivamente na prática pedagógica, investigamos se na coleção de livros destinada para tais cursos havia pertinência com a proposta programática da instituição.

\section{O Ginásio e os programas de Matemática}

O ensino secundário foi sistematizado em nível nacional por meio da Reforma Francisco Campos. O curso do primeiro ciclo era denominado fundamental, com cinco anos de duração. Após a Reforma Capanema, foi mantida a divisão em dois ciclos do ensino secundário, mas o primeiro ciclo recebeu o nome de ginásio e passou a contar com quatro anos.

A partir de uma análise histórica, Valente (2011) identifica que a matemática prática no curso secundário foi constituída por duas disciplinas que tiveram processos diferentes de constituição. São elas a Matemática do ginásio e a Matemática do colégio.

Valente (2004b, p. 16) afirma que o nascimento da Matemática do ginásio “[...] tem origem na apropriação do $1^{\circ}$ Movimento Internacional de Modernização do Ensino de Matemática ${ }^{2}$, feita a partir da herança de mais de um século deixada pelos exames parcelados de aritmética, álgebra e geometria”. A Matemática do colégio tem relação direta com a Reforma Francisco Campos e os cursos complementares.

A configuração em uma única disciplina deu-se inicialmente no âmbito do Colégio Pedro II, com o professor Euclides Roxo ${ }^{3}$, que exercia a função de diretor do externato do referido colégio, além de ter atuado como participante da elaboração do projeto de reconfiguração da Matemática na Reforma Francisco Campos.

A proposta de Euclides Roxo estava baseada nas propostas do Congresso Internacional de Matemáticos ocorrido em Roma, no ano de 1908 e estava inserida na perspectiva do Movimento Internacional de Reforma do Ensino de Matemática. A partir desse movimento, foi criada uma comissão para tratar da temática do ensino da disciplina, chamada de Internationale Mathematische Unterrichtskomission (IMUK) ou Commision Internationale de L'Enseignement Mathématique (CIEM). Entre os objetivos dessa reforma, estava a introdução de noções básicas de quantidades variáveis e dependência funcional nos temas de ensino da matemática e também de uma reorientação

\footnotetext{
${ }^{2}$ Foi um movimento criado em 1908 que apresentava propostas para reforma curricular da disciplina de Matemática para o ensino secundário.

${ }^{3}$ Foi professor de Matemática e diretor do Colégio Pedro II. Em 1927, propôs uma mudança radical no ensino de Matemática da instituição.
} 
dos métodos de ensino no sentido da intuição e das aplicações (SCHUBRING, 1999). Essas ideias se baseavam na reforma realizada na Alemanha por Felix Klein ${ }^{4}$, um dos matemáticos responsáveis também por apresentar uma discussão em nível internacional sobre o ensino de matemática.

Euclides Roxo tentou reunir tendências do movimento de reforma internacional, relativas a três questões principais: "metodologia, seleção de doutrina e finalidade de ensino" (VALENTE, 2004a, p. 101).

Os programas de Matemática do curso fundamental contemplavam em sua maior parte uma construção do conhecimento a partir do intuitivo até a sua consolidação nas séries posteriores.

Em 1939, o ministro Gustavo Capanema deu início aos estudos para a elaboração de uma nova reforma para o ensino secundário. Segundo Dassie (2001), dentre os documentos que o ministro analisou, estava um relatório elaborado pelo Instituto Nacional de Estudos Pedagógicos (INEP) sobre educação escolar brasileira no período entre 1932 a 1936, uma proposta do Colégio Pedro II e um relatório sobre legislação do ensino secundário nos países europeus. Também analisou propostas que estavam presentes em cartas do Colégio Militar do Rio de Janeiro e cartas do padre Arlindo Vieira.

A Lei Orgânica do Ensino Secundário de 1942 previa a criação de comissões para elaboração dos programas das disciplinas que foram instituídas pela Portaria $\mathrm{n}^{\circ} 101$, de 27 de abril de 1942. Para a elaboração do programa de Matemática, foi designada uma comissão, que teve a participação de Euclides Roxo e outras personalidades, como o padre Arlindo Vieira, que apresentou modificações as quais, segundo ele, tornariam os programas mais viáveis para a "mocidade brasileira" (DASSIE, 2001).

Os programas foram expedidos em 11 de janeiro de 1942 pela Portaria Ministerial $n^{\circ} 170$. No entanto, alguns pontos essenciais defendidos por Euclides Roxo foram retirados. Dentre eles, destacam-se a noção de função nas séries iniciais do ginásio e a supressão do ensino simultâneo de Aritmética, Álgebra e Geometria em torno da noção de função (MARQUES, 2005). Assim, a estrutura que fazia a união dos três ramos desapareceu, mas foram mantidas as orientações metodológicas de como iniciar o ensino das primeiras séries utilizando a Geometria Intuitiva. Notamos que nas Instruções Metodológicas da reforma anterior era preconizado um ensino de Matemática para todos os ramos que se iniciava a partir da intuição até chegar a um rigor matemático.

A proposta do programa de Matemática para a Reforma Capanema foi produto de um trabalho coletivo, o que permitiu um diálogo entre professores para elaborar o projeto que levou em consideração a proposta da Reforma anterior, baseada nas ideias de Euclides Roxo. Nessa nova

\footnotetext{
${ }^{4}$ Matemático alemão que viveu entre 1849 a 1925 . Realizou pesquisa em Matemática Pura especialmente na área de geometria não euclidiana e nas interligações entre a Teoria de Grupos e geometria. Também foi responsável por estudos relacionados à Educação Matemática, e divulgou uma proposta curricular que colocava o conceito de função no centro do processo da aprendizagem da matemática escolar na Alemanha.
} 
elaboração, foram confrontadas as ideias do próprio Euclides com a posição dos militares ${ }^{5}$, que achavam indispensável o desdobramento da disciplina de Matemática em Aritmética, Álgebra e Geometria, além do posicionamento do padre Arlindo Vieira, professor do Colégio Santo Inácio. Dessa forma, as propostas modernizadoras para o ensino da matemática sofreram alterações especialmente em relação ao ensino da noção de função, desde as primeiras séries do curso ginasial, que foram retiradas do programa. Outros conteúdos foram alocados no segundo ciclo do curso secundário.

Os programas de Matemática da Reforma Capanema, se comparados à Reforma Francisco Campos, apresentavam propostas mais enxutas, mas preservavam alguns tópicos. A seguir, apresentaremos o programa por série e fazer algumas considerações sobre cada um deles.

O programa da $1^{\text {a }}$ série estava estruturado em dois ramos: Geometria Intuitiva: noções fundamentais, sólidos geométricos, superfícies, linhas planos, ângulos, posições relativas, figuras geométricas, polígonos, círculo, poliedros e corpo redondo; e Aritmética Prática: número, operações básicas, múltiplos e divisores, fração ordinária e operações, fração decimal e operações, números complexos. Comparando o programa com o curso fundamental da Reforma Francisco Campos, verificamos que foi mantida a iniciação geométrica por meio da intuição. Foram retirados assuntos como cálculo mental, sistema métrico e raiz quadrada. Além disso, essa série não contemplava mais conteúdos de Álgebra.

O programa da $2^{\mathrm{a}}$ série estava dividido em: Geometria Intuitiva: área e volume; e Aritmética Prática: sistema métrico, potência e raízes, razão e proporção, problemas sobre grandezas proporcionais. A Geometria, comparando-a à Reforma Francisco Campos, ficou mais enxuta, no entanto o caráter intuitivo foi preservado na apresentação dos assuntos. Entre os conteúdos geométricos que foram deslocados para outras séries estavam: triângulos, quadriláteros, semelhanças, relações no triângulo retângulo. Nessa série, foi introduzido o estudo de sistemas métricos. Além disso, houve a inserção de assuntos relacionados à Aritmética, como potências e raízes. Se compararmos ao programa da reforma anterior, verificamos que conteúdos relacionados à Álgebra foram retirados.

O programa da $3^{\mathrm{a}}$ série estava assim estruturado: Álgebra: números relativos, expressões algébricas, operações algébricas, frações algébricas, equação do $1^{\circ}$ grau; e Geometria Dedutiva: introdução à geometria dedutiva, a reta, ângulos, triângulos, quadriláteros, o círculo. Nessa série, a Geometria era vista a partir do caráter mais formal com base em proposições e demonstrações. Nesse programa, também constavam como conteúdo as construções geométricas, que não estavam presentes

${ }^{5}$ Os militares tiveram um papel importante nas críticas as propostas de Euclides Roxo. As escolas militares eram contrárias a elas. 
de forma explícita em nenhuma série da reforma Francisco Campos, nem nas instruções metodológicas. O ensino da Álgebra iniciava-se a partir da $4^{\mathrm{a}}$ série, bem diferente da Reforma anterior, uma vez que os conteúdos algébricos apareciam desde a primeira série e com forte articulação com a noção de função que estava impregnada nas orientações para tal proposta. Outrossim, os números relativos também passaram a ser ensinados a partir dessa série, assim como constavam na primeira série da antiga proposta.

O programa da $4^{\mathrm{a}}$ série estava estruturado da seguinte forma: Álgebra: equação e desigualdade do $1^{\circ}$ grau, números irracionais e equação do $2^{\circ}$ grau; e Geometria Dedutiva: linhas proporcionais, semelhança, relações métricas no triângulo retângulo, relações métricas no círculo, polígonos regulares e áreas planas. Identificamos, nessa série, a presença do estudo de números irracionais e de equação do $2^{\circ}$ grau, enquanto na Reforma Francisco Campos eram ensinados nas séries anteriores. Notamos que alguns conteúdos contemplados no passado deixaram de o ser nesse ciclo do secundário. Foram incorporados ao segundo ciclo. Apesar de o estudo de funções estar ausente, é fácil verificar a presença da representação gráfica no plano cartesiano e da resolução de sistemas de $1^{\circ}$ grau utilizando o recurso gráfico.

De acordo com Dassie (2001), também foram produzidas instruções pedagógicas para esses novos programas, mas não foram expedidas por Gustavo Capanema. Marques (2005) afirma que o programa da Reforma Capanema se caracterizou por suprimir o ensino simultâneo dos três ramos da matemática em torno da noção de função e que representou, segundo Dassie (2002), um recuo das ideias modernizadoras de Euclides Roxo implementadas na reforma Francisco Campos.

Após o fim da Era Vargas, não foram realizadas novas reformulações no ensino secundário. Em 1951, com o retorno de Getúlio Vargas à presidência, assumiu como Ministro da Educação e Saúde, Ernesto Simões Filho, que propôs uma reformulação dos programas das disciplinas e das orientações pedagógicas para o ensino secundário. O objetivo era traçar um programa mínimo que pudesse ser cumprido pelos professores, uma vez que os programas da Reforma Capanema eram considerados extensos. Os programas mínimos de Matemática para o ginásio foram propostos pela Portaria Ministerial no 966, de 2 de outubro de 1951. No geral, a distribuição dos conteúdos nos programas era diferente das reformas anteriores, no entanto não foi inserido nenhum conteúdo novo.

\section{O programa de Matemática dos cursos industriais básicos}

Os cursos industriais básicos da ETN funcionaram entre 1942 a 1964, e, durante todo esse período, encontramos um único programa no Relatório da instituição de 1946, que também apresentava os programas de outras disciplinas. A partir de 1960, a escola deixou de realizar processo seletivo para esses tipos de curso. Em 1961, os cursos industriais básicos passaram a se chamar 
ginásio industrial pelo Decreto $\mathrm{n}^{\mathrm{o}}$ 50492, de 25 de abril de 1961. E, no ano de 1964, os últimos alunos desse ciclo se formaram. A escola passou a ofertar apenas cursos técnicos nesse momento.

A Lei Orgânica do Ensino Industrial tinha como objetivos:

Art. $4^{\circ} \mathrm{O}$ ensino industrial, no que respeita à preparação profisssional do trabalhador, tem as finalidades especiais seguintes:

1. Formar profissionais aptos ao exercício de ofícios e técnicas nas atividades industriais.

2. Dar a trabalhadores jovens e adultos da indústria, não diplomados ou habilitados, uma qualificação profissional que lhes aumente a eficiência e a produtividade.

3. Aperfeiçoar ou especializar os conhecimentos e capacidades de trabalhadores diplomados ou habilitados.

4. Divulgar conhecimentos de atualidades técnicas (BRASIL, 1942).

Tais finalidades podem ser consideradas explícitas com relação à legislação, e expressam o que governo e sociedade esperavam da formação dos alunos. No entanto, não podemos considerar apenas esses objetivos como elucidado por Chervel (1990). Uma vez que ele salienta que esse problema é complexo e sutil. Dessa forma, ainda existem as finalidades impressas nos documentos da escola e pelos docentes da disciplina.

Como encontramos esse programa de 1946, surgiram algumas questões com relação aos conteúdos. Dentre elas, não identificamos qual foi o programa em prática de 1942 até 1944, uma vez que, segundo o relatório, só foi enviado pela Divisão de Ensino Industrial (DEI) uma proposta em 1944.

Não localizamos o programa enviado pela DEI. No entanto, o trabalho de Antônio Henrique Pinto sobre o ensino de Matemática na Escola Técnica de Vitória (ETV) revela-nos um programa datado de 1944, que foi apresentado no jornal da instituição como sendo enviado pela DEI. Como verificado no relatório da ETN, o programa da DEI tinha muitas revisões de conteúdos, assim como o da ETV também apresentava essa conformação, por isso havia alguns indícios de que esse possa ter sido o programa enviado pela DEI para todas as escolas técnicas federais, embora ainda não tenha sido possível confirmar tal fato.

A Lei Orgânica do Ensino Industrial previa que os programas seriam organizados e deveriam ser periodicamente revistos. Além disso, deveriam conter os métodos e processos pedagógicos adequados ao ensino. Observamos por nossa busca que não foi o que ocorreu, e o programa apresentado em 1946 da ETN pode ter sido um programa modelo para as outras escolas do sistema federal de ensino. $\mathrm{O}$ art. 38 do decreto ainda afirma que o programa deveria ser cumprido na sua totalidade.

Os programas de todas as disciplinas dos cursos da instituição foram apresentados no Relatório de 1946, e “[...] esses programas foram elaborados pelos professores deste estabelecimento 
e têm sido melhorados à medida que sua aplicação tem demonstrado essa necessidade, representando, assim, em seu aspecto atual, uma fase avançada de uma experiência vivida" (RELATÓRIO, 1946, p. 6). A seguir, apresentamos o programa destinado à Matemática dos cursos industriais básicos.

\begin{tabular}{|c|c|}
\hline Série & Conteúdos \\
\hline \multirow[t]{2}{*}{$1^{\mathrm{a}}$} & $\begin{array}{l}\text { Aritmética: Numeração de inteiros e decimais; Operações fundamentais de inteiros e decimais; } \\
\text { Divisibilidade; Números Primos; Máximo Divisor Comum e Mínimo Múltiplo Comum; Frações } \\
\text { Ordinárias e Decimais; Sistema métrico decimal; Unidades inglesas usuais; Números } \\
\text { Complexos. }\end{array}$ \\
\hline & $\begin{array}{l}\text { Geometria Intuitiva: Corpo, superfície, linha, ponto; Plano, reta, semirreta, segmento de reta; } \\
\text { Linha Poligonal; Linha Curva; Posições Relativas de duas retas; Figuras Planas: ângulos, } \\
\text { triângulos, quadriláteros, polígonos, círculo; Poliedros; Corpos Redondos. }\end{array}$ \\
\hline \multirow[t]{2}{*}{$2^{\mathrm{a}}$} & $\begin{array}{l}\text { Aritmética: Potências e raízes; Raiz quadrada e raiz cúbica de inteiros e decimais; raiz quadrada } \\
\text { e raiz cúbica por meio de tabelas; Razões e Proporções; Regra de Três; Divisão Proporcional; } \\
\text { Regra de Sociedade; Porcentagem; Juros Simples. }\end{array}$ \\
\hline & $\begin{array}{l}\text { Geometria Intuitiva: Perímetro e áreas do retângulo, quadrado, paralelogramo, triângulo, } \\
\text { losango e trapézio; Retificação da Circunferência; Áreas do círculo, coroa, setor circular e de } \\
\text { figuras irregulares; Áreas e volumes do prisma, pirâmide, tronco de pirâmide, cilindro, cone, } \\
\text { tronco de cone e esfera. }\end{array}$ \\
\hline \multirow[t]{2}{*}{$3^{a}$} & $\begin{array}{l}\text { Álgebra: Notação Algébrica; Expressões Algébricas; Operações Algébricas; Frações } \\
\text { Algébricas; Equações e problemas do } 1^{\circ} \text { Grau com uma incógnita. }\end{array}$ \\
\hline & $\begin{array}{l}\text { Geometria Dedutiva: Preliminares; Ângulos; Triângulos; Perpendiculares e Obliquas; } \\
\text { Paralelas; Soma dos ângulos de um triângulo e de um polígono convexo; Quadriláteros; } \\
\text { Polígonos; Círculo; Medida dos ângulos; Noções sobre funções trigonométricas; Emprego da } \\
\text { tábua de senos, cossenos e tangentes naturais. }\end{array}$ \\
\hline \multirow[t]{3}{*}{$4^{a}$} & $\begin{array}{l}\text { Álgebra: Equações simultâneas do } 1^{\circ} \text { Grau. Métodos de Eliminação; Problemas do } 1^{\circ} \text { grau de } \\
\text { várias incógnitas; Cálculo dos radicais; Equações do } 2^{\circ} \text { grau. }\end{array}$ \\
\hline & $\begin{array}{l}\text { Geometria Dedutiva: Linhas proporcionais; Semelhança; Escala; Triângulos semelhantes; } \\
\text { Propriedades das bissetrizes de um triângulo; Relações métricas nos triângulos; Teorema de } \\
\text { Pitágoras; Relações métricas no círculo; Polígonos regulares, inscritos e circunscritos. }\end{array}$ \\
\hline & $\begin{array}{l}\text { Trigonometria: Funções trigonométricas e sua variação; Redução à primeira circunferência e } \\
\text { ao primeiro quadrante; Relações Fundamentais; Funções trigonométricas de certos arcos; } \\
\text { Tábuas trigonométricas naturais; Resolução de triângulos por meio dessas tábuas. }\end{array}$ \\
\hline
\end{tabular}

Fonte: Relatório da ETN (1946, p. 38-39).

Esse programa foi organizado pelo professor José Ernani de Lima. Ele nasceu no dia 14 de abril de 1895, na cidade de Itajubá, no estado de Minas Gerais. Era filho de Luiz Ramos de Lima e Orminda Rennó de Lima. Estudou no externado São José, de sua cidade natal, e graduou-se em engenharia mecânica e elétrica pelo Instituto Eletrotécnico e Mecânico de Itajubá, em 1917. Foi professor de Matemática da Escola Normal de Artes e Ofícios Venceslau Brás e do Colégio Santo Inácio, entre outros. Como a Escola Normal foi transformada em ETN, passou a integrar o corpo docente da escola. Atuou na instituição até 1956, quando se aposentou.

De acordo com o Relatório da ETN de 1946, o programa era uma adequação de uma proposta enviada pela DEI. Os professores da instituição consideraram que a proposição continha itens muito repetitivos, pois, os assuntos eram revisados ao longo das séries, o que despendia muito tempo. No 
programa da ETN, notamos que havia divisão dos conteúdos entre as áreas de Aritmética, Álgebra e Geometria e Trigonometria.

Foi possível levantar a hipótese de que o programa em vigência poderia ter sido o mesmo que o do ensino secundário, uma vez que o professor responsável pela disciplina, José Ernani, era docente do Colégio Santo Inácio, onde trabalhava o padre Arlindo Vieira, que contribuiu para a elaboração do projeto do programa do curso ginasial da Reforma Capanema. Outra hipótese foi a de que, como o docente também atuou na antiga Escola Normal de Artes e Ofícios Venceslau Brás, ele tenha utilizado o programa dessa instituição.

Com relação ao programa de 1946 é fácil constatar que os conteúdos são apresentados de forma bem clara e sucinta, não foram criadas subdivisões com as temáticas propostas. Os conteúdos estão separados em cinco áreas: Aritmética, Geometria Dedutiva, Geometria Intuitiva, Álgebra e Trigonometria. Nas séries iniciais, a ênfase foi dada na Aritmética e na Geometria Intuitiva. A Álgebra é introduzida no terceiro ano, e também faz parte do quarto. Já a temática de trigonometria se encontra apenas no último ano.

\section{Análise do programa de Matemática da ETN (1946)}

De acordo com Goodson (1997, p. 26), tem-se que é “[...] necessário empreender mais investigações sobre o currículo escolar numa perspectiva comparada”. Nessa visão estamos analisando os currículos escritos (programas) da disciplina de Matemática da ETN com os programas do ensino ginasial que foram marcados pelas Reformas educacionais e outros programas para cursos industriais básicos. Tal comparação entre os programas se deu pelo fato de Valente (2011) elucidar que havia uma disciplina chamada matemática do ginásio. Dessa forma, fez se a escolha para verificar se a disciplina da ETN era a mesma do ginásio ou não.

Ao confrontarmos o programa de Matemática dos cursos industriais básicos da ETN com o programa do curso ginasial, da Reforma Capanema, percebemos muitas similaridades nos conteúdos e na sua distribuição ao longo das séries. Entre os itens que estão em ordem diferente, estava a temática de sistemas métricos, que no programa da ETN era apresentado a partir da primeira série, o que fazia sentido pelas necessidades de mensuração necessária aos cursos industriais, diferentemente da que era apresentada no programa do Ginásio. Outro item que também faz parte do programa apresentado na escola é a temática de Trigonometria no Ciclo, que faz parte da $4^{\mathrm{a}}$ série e que não estava presente no programa apresentado para o ensino secundário.

Também analisamos e confrontamos os programas da ETN e o Programa Mínimo apresentado em 1951 para o ginásio. Os conteúdos do segundo programa foram parecidos com o programa da Reforma Capanema, mas a distribuição dos conteúdos estava diferente e sem a divisão por áreas. 
Dessa forma, ao compararmos o programa da escola com o do Programa Mínimo de 1951, notamos que havia uma grande diferença na distribuição dos conteúdos, com exceção da primeira série.

Ao realizarmos a comparação desse programa de 1946 com os que foram apresentados para escolas técnicas, de Pinto (2006), Moura (2012) e do III Congresso Brasileiro de Ensino de Matemática (Ministério da Educação e Cultura, 1959), identificamos que os conteúdos apresentavam similaridades, mas a distribuição possuía algumas diferenças. Dentre outros itens, a Trigonometria foi uma constante nos programas. A questão relacionada à metrologia de todos os programas estava inserida desde a primeira série, assim como a valorização da Geometria. Os programas já apresentavam conteúdos de Álgebra desde a $2^{\mathrm{a}}$ série, o que era diferente do programa da ETN, que inseria a temática apenas a partir da $3^{\mathrm{a}}$ série.

Para verificarmos se o programa encontrado no Relatório (1946) foi aplicado em sala é preciso constatar se ele foi executado na ETN. Goodson (1997) afirma que não existe uma relação direta do que está prescrito no currículo e sua realização na sala de aula. Por isso, a necessidade de se verificar nas práticas pedagógicas se os conteúdos foram de fato aplicados em sala de aula. Viñao (2008) considera a prática profissional com um dos itens importantes para o código disciplinar. Nessa dimensão, podemos constatar como era ensinada a disciplina. Na visão de Chervel (1990), há necessidade de verificar se os objetivos estabelecidos foram colocados em prática a partir da realidade da sala de aula. Tal prática poderia ser encontrada em diários, livros e cadernos. A partir dos arquivos e da associação de ex-alunos da ETN, obtivemos a informação que os alunos utilizavam apostilas e $\operatorname{livros}^{6}$, e, por isso, justificou-se a razão para não encontrarmos cadernos dos alunos dessa instituição.

Os manuais didáticos são fontes importantes para analisarmos as práticas da disciplina no ensino industrial, devido à carência de outros materiais. Dessa forma, constatamos que a análise da prática educacional da instituição que estamos analisando se devem ser encontradas em tais materiais. Julia (2001) considera que o manual didático não é nada sem o uso que lhe é dado tanto pelos professores como pelos alunos, e verificamos que em alguns diários e planos de curso o ensino estava alinhado com os manuais e programas elaborados pelos docentes. Chartier (2002) identifica que os livros configuram objetos de circulação e, assim, tornam-se veículos de transmissão de ideias que trazem valores e/ou comportamentos. Chervel (1990) demonstra que os livros são importantes fontes de estudo, pois eles apresentam conteúdos, terminologia adotada, organização da sequência e uma padronização de manuais de um determinado período, que podem contribuir para a constituição de uma vulgata ${ }^{7}$. Identificamos como manuais didáticos utilizados na ETN nos cursos industriais duas

\footnotetext{
${ }^{6}$ Destacamos que os exercícios eram realizados nos próprios manuais didáticos.

${ }^{7}$ Para Chervel (1990) em determinadas épocas o ensino dispensado por professores, grosso modo, é muito parecido, e quando os manuais didáticos têm muita similaridade, isso acontece devido ao fato de se constituir uma vulgata.
} 
apostilas e uma coleção de livros. Os livros foram baseados nas apostilas criadas pelo curso de tipografia e eram distribuídas gratuitamente para os alunos.

A coleção Caderno de Matemática foi publicada em duas edições, e estava dividida em quatro volumes, que correspondia a cada uma das séries dos cursos industriais básicos. No presente estudo, utilizamos os quatro volumes da segunda edição, pois não encontramos todos os exemplares da primeira. Essa coleção foi financiada pela Comissão Brasileira Americana de Ensino Industrial (CBAI) e era distribuída de forma gratuita. O autor da coleção foi o professor Arlindo Clemente ${ }^{8}$. Ele atuou na ETN como docente e chefe da disciplina, além disso, era engenheiro formado pela Escola Nacional de Engenharia.

No que diz respeito aos conteúdos apresentados nos quatro volumes da coleção, percebemos que estavam alinhados com o programa de Matemática da ETN, de 1946, para os cursos industriais básicos. Havia, no entanto, uma pequena variação na ordem de alguns conteúdos. O tema de Funções Trigonométricas, que no programa deveria ser oferecido na $3^{\mathrm{a}}$ série, foi encontrado apenas no livro da $4^{\mathrm{a}}$ série. Além disso, notamos a inserção de Representação Gráfica e Funções também na $4^{\mathrm{a}}$ série, o que não fazia parte da gama de conteúdos do programa. O conteúdo de Equações do $2^{\circ}$ grau não foi encontrado nos materiais didáticos, o que nos indica que ele pode ter sido abolido do programa, mas notamos que tal assunto era abordado no programa dos cursos técnicos, o que pode ter facilitado à retirada desse assunto dos cursos industriais básicos (MACIEL, 2018).

Consideramos que os manuais didáticos utilizados em nossa investigação foram materiais inovadores para o ensino industrial, que surgiram no âmbito da escola, mas também foram disponibilizados para as outras escolas técnicas do país. Segundo Valente (2007), o fato de ser um material inovador representa uma condição necessária para a escrita da trajetória histórica de um determinado saber. Assim, tais manuais encontrados na instituição nos auxiliaram a escrever a trajetória de sua matemática.

\section{Discussões sobre a disciplina de Matemática}

Viñao (2008) afirma que os discursos sobre o valor formativo e utilidade são um dos componentes do código escolar, e que esses discursos têm importância para apresentação da relevância das disciplinas, além de serem mecanismos para adequar os conteúdos a demandas da sociedade especialmente do setor produtivo. Eles podem ser pronunciados em eventos e comunicações. Separamos dois discursos feitos sobre a Matemática no ensino industrial que ocorreram em um Congresso e numa revista destinada a essa modalidade de ensino.

\footnotetext{
${ }^{8}$ Era engenheiro formado pela Escola Nacional de Engenharia, atuou como professor da instituição desde 1946. Produziu livros e apostilas para o ensino industrial.
} 
Em 1959, ocorreu na cidade do Rio de Janeiro, na época era o Distrito Federal, o III Congresso Brasileiro de Ensino de Matemática ${ }^{9}$. O evento teve comissões técnicas separadas por áreas como: ensino secundário, ensino normal e primário, ensino comercial, formação e aperfeiçoamento do professor secundário, problemas gerais ligados ao ensino da Matemática, ensino pré-universitário e ensino industrial. Os seguintes professores da ETN fizeram parte da comissão do ensino industrial: Arlindo Clemente, João Dias dos Santos Júnior e Flávio Guerra. Entre as conclusões obtidas no congresso, estava que o planejamento da disciplina de Matemática para os cursos do ensino industrial deveria ter como critérios: objetivos dos cursos; coordenação das unidades a serem lecionadas; e flexibilidade da disciplina para permitir adaptação nas diferentes regiões do país e da evolução da matemática. Outra consideração que se levantou no evento foi a correlação entre a disciplina de Matemática e as de cultura técnica dos cursos industriais. O congresso aprovou a seguinte recomendação:

\begin{abstract}
Além de sua importante função formativa, a Matemática nos cursos industriais deve ser encarada como instrumento imprescindível a solução de problemas que os aprendizes encontrarão durante o curso e, principalmente, daqueles que, sem dúvida, surgirão no decorrer de sua vida técnico-profissional (MINISTÉRIO DA EDUCAÇÃO E CULTURA, 1959, p. 225).
\end{abstract}

Outro ponto importante expresso foi em relação ao planejamento da disciplina, que deveria colocar os objetivos inicialmente, identificando o que deveria ser ensinado aos alunos e como esses poderiam contribuir para a aquisição de conhecimentos necessários à resolução de problemas relacionados à oficina.

Os autores dessa última tese consultaram professores de outras disciplinas, como Desenho, Ciências e Tecnologia, que tinham forte conexão com a prática nas oficinas, com o intuito de buscar nas experiências deles os conhecimentos indispensáveis ao entrosamento com a Matemática.

O professor Arlindo Clemente escreveu um texto sobre o ensino de matemática nas escolas técnicas industriais. O autor relatou que, ao se falar da disciplina de Matemática no ensino industrial, não se pode deixar de falar da atuação dos docentes que, muitas vezes, atuam tanto no ensino industrial como no ensino secundário ${ }^{10}$. E que esse profissional acaba por levar defeitos e virtudes de uma modalidade para outra. Em outra afirmação, Clemente (1948) realiza uma comparação entre as duas modalidades, afirmando que o professor do ginásio recebe formação pedagógica para atuar nesse tipo de curso, e que, naquela época, existia uma estrutura para a sua atuação. No entanto, para ele, o

\footnotetext{
${ }^{9}$ As edições anteriores deste congresso não contemplavam a Matemática no ensino industrial.

${ }^{10}$ Essas modalidades tinham articulação de acordo com a Reforma Capanema.
} 
professor do ensino industrial precisava ser autodidata. Na visão de clemente, as modalidades de ensino eram distintas e, assim, disciplinas ofertadas em cada uma também eram diferentes.

Além disso, o referido professor afirma que:

O raciocínio matemático é que transformará o antigo operário, empiricamente formado, no operário moderno muito mais capaz, por que com muito maior capacidade intelectual. E, sem dúvida, esta parcela de cultura é aquela que dará ao operário a possibilidade de ligar seu cérebro às mãos. Esta é a função da matemática no ensino industrial (CLEMENTE, 1948, p. 87).

Clemente (1948) apresenta algumas das finalidades da escola e, até mesmo, da disciplina: a formação de um operário. Nesse ponto, a finalidade se contrapõe àquela do ensino secundário que visava ao ingresso no ensino superior. Dessa forma, toda a vida acadêmica e produção dos materiais didáticos pelo autor seguiam essa linha de pensamento na sua elaboração e na escolha dos conteúdos que fizeram parte desses materiais. $\mathrm{O}$ autor finaliza a matéria, considerando que a disciplina de Matemática no ensino industrial para produzir os frutos precisa de: formação pedagógica para os professores, bibliografia eficiente, revisão dos programas e revisão dos horários, a fim de permitir aos alunos, maior trabalho pessoal. Essas etapas são levantadas a partir de toda a argumentação apresentada por Clemente (1948) no texto. No que se refere aos horários, o autor afirma que os alunos entravam na escola muito cedo e saíam quase de noite e, com isso, não tinham tempo para estudar em casa e realizar exercícios, devido ao cansaço físico e mental que a escola exigia por ser em tempo integral.

Ao verificar os discursos produzidos no III Congresso, observamos a necessidade de uma matemática prática aos alunos. Não encontramos no programa de 1946 uma proposta específica para a indústria. Tal proposta pode ter sido concebida para a prática pedagógica. Mas percebemos que havia dentro do evento a necessidade de adequação e articulação com a oficina.

No discurso de Clemente, verificamos que o autor de livro considerava a especificidade do ensino industrial necessidade de ter formação docente para isso, materiais e adequação devido ao fato dos alunos passarem o dia na escola e a dificuldade em realizar atividades em casa.

\section{Considerações Finais}

No que se refere à comparação dos conteúdos do curso industrial básico com o ginásio, constatamos que havia uma similaridade da nomenclatura dos conteúdos. No entanto, Vinão (2008) afirma que, mesmo com denominação de conteúdos semelhantes, nem sempre são oferecidos conteúdos idênticos, pois a nomenclatura constitui uma carta de apresentação "social e acadêmica". 
Ao analisarmos os manuais didáticos desse segmento de ensino, notamos que, apesar da similaridade dos nomes dos conteúdos com o ginásio, a forma de expor o assunto era diferente.

Os materiais produzidos (apostilas e livros) para tais cursos na ETN nos permitiram constatar que os conteúdos fixados pelo programa de 1946 fizeram parte da prática pedagógica. Além disso, tais conteúdos nas apostilas e livros sempre que possível apresentavam problemas e exercícios aplicados nas áreas correlatas dos cursos, demonstrando, assim, uma preocupação com a formação profissional dos alunos e demonstrando a finalidade do ensino industrial, que era a de preparar para a atividade profissional.

\section{Referências}

BLOCH, M. L. B. Apologia da história, ou, O ofício de historiador. Tradução de André Telles. Rio de Janeiro: Jorge Zahar, 2001.

BRASIL. Ministério da Educação e Saúde. Decreto-lei no 4073, de 30 de janeiro de 1942. Lei Orgânica do Ensino Industrial. Diário Oficial da União. Rio de Janeiro, DF, 9 fev. 1942. n. 33, Seção 1. p. 1997-2002.

CERTEAU, M. A. Escrita da história. Rio de Janeiro: Forense, 2011.

CHARTIER, R. A história cultural: entre práticas e representações. Lisboa: Difel, 2002.

CHERVEL, A. História das disciplinas escolares: reflexões sobre um campo de pesquisa. Teoria \& Educação, Porto Alegre, n. 2, 1990.

CLEMENTE, A. Sôbre o ensino da matemática nas escolas de ensino industrial. BOLETIM DO CBAI, Rio de Janeiro, v. 2, n. 4, p. 86-87, 1948.

CUNHA, L. A. Ensino secundário e ensino industrial: Análise da influência recíproca. Síntese: Revista de Filosofia, v.7, n. 18, p. 49-71, 1980.

DALLABRIDA, N. A reforma Francisco Campos e a modernização nacionalizada do ensino secundário. Educação, Porto Alegre, v. 32, n. 2, p. 185-191, maio/ago. 2009.

DASSIE, B. A. A matemática do curso secundário na reforma Gustavo Capanema. 2001. $170 \mathrm{f}$. Dissertação (Mestrado em Matemática) - Departamento de Matemática da Pontifícia Universidade Católica do Rio de Janeiro, Rio de Janeiro, 2001.

GOODSON, I. A construção social do currículo. Lisboa: Educa, 1997.

JULIA, D. A cultura escolar como objeto histórico. Revista Brasileira de História da Educação, Campinas, n. 1, p. 9-44, 2001.

LE GOFF, J. História e memória. Tradução de Bernardo Leitão et al. Campinas: UNICAMP, 1990. 
MACIEL, P. R. C. A Matemática na Escola Técnica Nacional (1942-1965): uma disciplina diferente? 2018. 225f. Tese (Doutorado em Ciência, Tecnologia e Educação) - Rio de Janeiro: Centro Federal de Educação Tecnológica Celso Suckow da Fonseca, CEFET/RJ, 2018.

MARQUES, A. S. Tempos pré-modernos: a matemática escolar dos anos 1950. 150 f. Dissertação (Mestrado em Educação Matemática) - Programa de Pós-Graduação em Educação Matemática, Pontíficia Universidade Católica de São Paulo. São Paulo, 2005.

MINISTÉRIO DA EDUCAÇÃO E CULTURA. Anais do III Congresso Brasileiro do Ensino da Matemática. Rio de Janeiro: CADES, 1959.

MOURA, E. C. M. O ensino de matemática na Escola Industrial de Cuiabá/MT no período de 1942 a 1968. 2012. 127 f. Dissertação (Mestrado em Educação Matemática). Instituto de Geociências e Ciências Exatas do Campus de Rio Claro, Universidade Estadual Paulista Júlio de Mesquita Filho Rio Claro, 2012.

PINTO, A. H. Educação matemática e formação para o trabalho: práticas escolares na Escola Técnica de Vitória - 1960 a 1990. 2006. 344f. Tese (Doutorado em Educação)- Universidade Estadual de Campinas, Faculdade de Educação, Campinas, SP, Brasil, 2006.

RELATÓRIO DA ETN. Arquivo do CEFET/RJ, caixa 64.4.4, pasta ETN1.01.013, Relatório da ETN, 1946.

ROMANELLI, O. História da educação no Brasil. Petrópolis, RJ: Vozes, 2013.

SCHUBRING, G. O primeiro movimento internacional de reforma curricular em matemática e o papel da Alemanha: um estudo de caso na transmissão de conceitos. Zetetiké. Campinas, v. 7, n. 11, p. 29-50, jan./jun. 1999.

VALENTE, W. R. A matemática do ensino secundário: duas disciplinas escolares?. Revista Diálogo Educacional (PUCPR. Impresso), v. 11, p. 645-662, 2011.

2007.

. História da educação matemática: interrogações metodológicas. REVEMAT, v. 2, p. 28-49,

Euclides Roxo e a modernização do ensino de matemática no Brasil. Brasília, DF: UNB, 2004a.

(org.). O nascimento da matemática do ginásio. São Paulo: Annablume, 216. 2004b.

VIÑAO, A. A história das disciplinas escolares. Revista Brasileira de História da Educação, Maringá, v. 8, n. 3, p. 173-2015, jul. 2008. 